\title{
In transition: a new journey
}

\author{
Jacob I. Mackenzie ${ }^{1} \cdot$ Dieter Meschede $^{2}$
}

Received: 14 February 2021 / Accepted: 15 February 2021 / Published online: 6 March 2021

(c) The Author(s), under exclusive licence to Springer-Verlag GmbH Germany, part of Springer Nature 2021

\section{Smooth transitions}

Dear readers of Applied Physics B, after a little over 8 years, I am leaving the office of Editor-in-Chief. It has been a true professional as well as personal pleasure to work with the editorial board and our publisher to maintain this journal as a high-quality scientific repository by ensuring that decisionmaking was always based on scientific reasoning only-novelty and physical insight which is the ultimate interest of scientific authors. The stream of submissions has continued to evolve from its foundational topics on the laser itself and all variants of spectroscopy into an ever more widening range of applications enabled by photonic light sources and devices, rendering insight into many unexpected areas of physics for the Editor-in-Chief. Since lasers and photons are on their way to feed the leading technologies for the twenty-first century, this development will not stop. My best wishes are with Applied Physics B, Jacob Mackenzie, and its readers to take advantage of this excellent opportunity and further accompany scientific advances in the fields of Lasers and Optics!

As the incoming editor-in-chief, I see a daunting challenge ahead, though in part calmed by the excellent platform that has been built by my predecessors. Looking at the journey ahead reminds me of a time just over 2 decades ago when I wanted to research a change of direction in my career. Working then as an electro-optic engineer a few years out of university, I felt the need to return to academic pursuits and undertake a doctorate. At that time the only way I knew to explore the world of scientific literature was printed Abstracts archives in the library. Volumes and volumes lined the shelves, each covering a year of scientific publications for specific ranges of topics, requiring days of

Jacob I. Mackenzie

Editor_APHB@soton.ac.uk

University of Southampton, Southampton, UK

2 Institut für Angewandte Physik Universität Bonn, 53125 Bonn, Germany research just to uncover likely papers relevant to my field of interest, solid-state lasers. That was just the start of the process! Today, in seconds you can achieve what took days or weeks, just 25 years ago. The publishing landscape has been transformed dramatically and incredibly rapidly, along with so many other aspects of our daily lives, underpinned by lasers and optics that are driving the world wide web and are the core focus of this archival journal.

This year marks the 40th anniversary since the demarcation of the Springer-Verlag journal of Applied Physics into separate branches, Applied Physics A: Solids and Surfaces and Applied Physics B: Photophysics and Laser Chemistry, the latter changing the emphasis to Lasers and Optics in 1994. Founded and edited by H.K.V. Lotsch until 1995, the Editorship was then taken over by F. Träger until 2012 when the helm was passed to D. Meschede, all ably supported by T.W. Hänsch, who was a co-editor for 33 years (1983-2016) and who remains an Honorary Editor to this day. The journal's ethos was, and still is, to be a leading international periodical capturing key experimental and theoretical breakthroughs in the science of photons. Notable exemplars include the first papers on the now indispensable laser phase and frequency stabilisation technique [1], the disc laser [2], carrier-envelope phase control in ultra-short pulses [3], and ground-state-depletion fluorescence microscopy [4], with further seminal papers ranging from femtosecond-laser nano-surgery [5], through Terahertz imaging [6], to laser wakefield acceleration [7].

Stringent peer review through editorial and scientists' critique is fundamental in maintaining the quality and relevance of a journal and its content. We are proud to follow the guiding principle that this journal is steered by scientists for scientists, aiming to promulgate critical knowledge and insight within the field of lasers and optics. Our editorial board has a broad depth of expertise covering wide-ranging topics within the field and who will continue to strive for excellence in the selection of submissions for publishing. 


\section{Expectations and challenges for the future of publishing}

The creation of the internet has been transformative for the Information Age, not least for academic publishing. Information sharing became that much easier, accelerating knowledge transfer around the globe, augmented by the "open access" mantra, which marks another significant milestone in the journey of publishing. A difficult juggling act has ensued; 'quality versus quantity', along with the implementation of a workable business model that supports the integrity and sustainability of the scientific peer-review process. It has been a turbulent period in publishing over the past decade, with an influx of new journals arising out of the ease to publish online and the opportunity to capitalise on the 'need' for rapid dissemination and exploitation of new knowledge. This is driven by a steady growth in research funding globally and sponsor's impact metrics. In the face of fierce competition, adhering to a sustainable and credible publishing model, one that copes with the increasing flux of scientific papers whilst maintaining quality and attractiveness to readers and authors alike, continues to challenge publishers.

Scientific authors are currently presented with a smorgasbord of potential publishing routes, their decision often defined by the need to demonstrate impact for their sponsors and enabling career advancement. Therefore, a journal's impact-rating, speed in publishing, charges, and extent of distribution or dare we say it, marketing, are all crucial aspects in one's choice where to publish. In peer review, the sheer volume of papers written each year implies a greater burden on reviewers. Time pressures for this often-voluntary commission require publishers to continually expand their pool of potential reviewers, risking the quality and timeliness for receiving technically sound assessments of scientific novelty.

Ultimately it is for the readers that journals are produced. Here again, there are distinct challenges associated with expanding numbers of published works. Readers are themselves being inundated with notices of publications, from an increasing number of publishers, many unsolicited. Coupled with the intense daily pressures for scientists to progress their own research, the clamouring for their attention by the plethora of journals can be bewildering. It already is becoming easier to focus on just one topic area and selectively read across several journals rather than simply peruse all the papers on offer in just one: a trend that has a clear disadvantage in encouraging 'silo thinking' to the detriment of interdisciplinary innovations. Readers, authors, and publishers alike will need to consider just how to best use the opportunities of open access and the variations of knowledge sharing that come with it.
From an editorial perspective, the challenge for the journey ahead is to maintain a high standard while ensuring a fast response rate, so that authors feel their research will be widely accessible in a timely fashion. Our ambition is to bolster the attractiveness of this journal for the author, reviewer, and reader; providing a highly visible and robust podium for scientific dissemination, and, be sustainable for the publisher. A fine balance must be found in setting the "bar" sufficiently high that readers come to our journal searching for knowledge, aiming to achieve a ripple effect that those readers become our next authors. With our support, Springer Nature will need to navigate the turbulent waters of openaccess, promoting agreements such as 'Springer Compact', to manage the swing from a reader-to-author-pay commercial model. Clearly, here the editorial board must also play their part: as the interface between author and peer review, providing technical expertise and direction for the journal, and to be its ambassadors through scientific engagement. These will be very exciting times.

To conclude, as the incoming Editor-in-Chief, it is with deep sincerity that I thank Dieter Meschede, and past and present editors of Applied Physics B, for upholding its status and integrity through the years. Together, with the publishing staff and editorial boards, you have set this journal on sound foundations, ready to meet the challenges to be faced in the journey ahead.

\section{References}

1. R.W.P. Drever, J.L. Hall, F.V. Kowalski, J. Hough, G.M. Ford, A.J. Munley, H. Ward, Laser phase and frequency stabilization using an optical-resonator. ApplPhys B-Photophys Laser Chem 31(2), 97-105 (1983)

2. A. Giesen, H. Hugel, A. Voss, K. Wittig, U. Brauch, H. Opower, Scalable concept for diode-pumped high-power solid-state lasers. ApplPhys B-Laser Opt 58(5), 365-372 (1994)

3. H.R. Telle, G. Steinmeyer, A.E. Dunlop, J. Stenger, D.H. Sutter, U. Keller, Carrier-envelope offset phase control: a novel concept for absolute optical frequency measurement and ultrashort pulse generation. ApplPhys B-Laser Opt 69(4), 327-332 (1999)

4. S.W. Hell, M. Kroug, Ground-state-depletion fluorescence microscopy-a concept for breaking the diffraction resolution limit. ApplPhys B-Lasers Opt 60(5), 495-497 (1995)

5. A. Vogel, J. Noack, G. Huttman, G. Paltauf, Mechanisms of femtosecond laser nanosurgery of cells and tissues. ApplPhys B-Laser Opt 81(8), 1015-1047 (2005)

6. D.M. Mittleman, M. Gupta, R. Neelamani, R.G. Baraniuk, J.V. Rudd, M. Koch, Recent advances in terahertz imaging. ApplPhys B-Laser Opt 68(6), 1085-1094 (1999)

7. A. Pukhov, J. Meyer-ter-Vehn, Laser wake field acceleration: the highly non-linear broken-wave regime. ApplPhys B-Laser Opt 74(4-5), 355-361 (2002)

Publisher's Note Springer Nature remains neutral with regard to jurisdictional claims in published maps and institutional affiliations. 